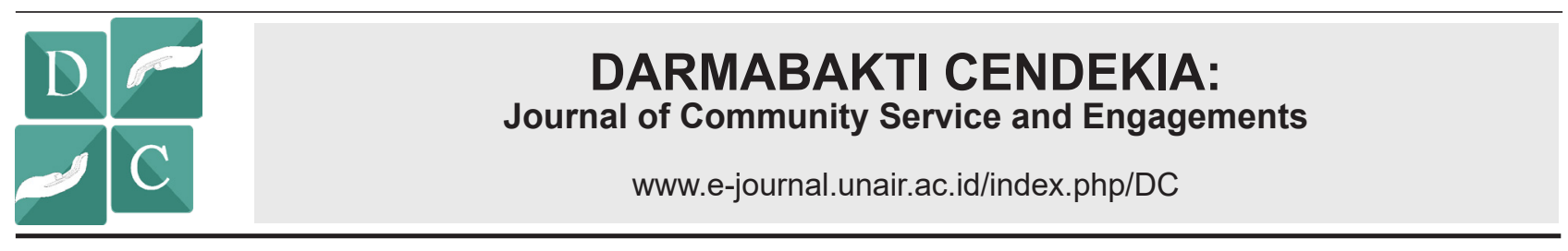

\title{
SOCIAL MEDIA ADVERTISING ASSISTANCE WITH PERSUASION CONCEPT - ELABORATION LIKELIHOOD MODEL (ELM) FOR SMES IN SURABAYA
}

\author{
PENDAMPINGAN PEMBUATAN IKLAN MEDIA SOSIAL DENGAN \\ KAIDAH PERSUASION CONCEPT - ELABORATION LIKELIHOOD \\ MODEL (ELM) PADA UKM DI SURABAYA
}

Phima Ruthia Dwikesumasari*, Maurisia Putri Permatasar回, Damar Kristantd遂

Study Program of Marketing Management, Faculty of Vocational Studies, Universitas Airlangga, Surabaya-Indonesia

\section{A B S T R A C T}

Background: Along with the development of digital media tools, the direction of marketing shifts from conventional to social media-oriented. However, this is not easily conducted by SME business circles. Many of them do not have high literacy, do not have IT coding skills. In addition, capitalizing as well as maintaining a website are costly for them. This fact encourages the SMEs to look at another opportunity, namely the use of social media. However, it proves that these SMEs have not utilized the use of social media with persuasive advertisements. Objective: This community service activity purposes to assist the SMEs in Surabaya creating their social media advertisements using the persuasion concept-elaboration likelihood model (ELM) to solve the problems in marketing. Methods: The methods used are (1) discussion; (2) training and assisting in making advertisements; (4) evaluating/monitoring. As a result of this community service activity, the SMEs that have been assisted are able to create persuasive social media advertisements and can improve their marketing performance. Results: These MSME owners are able to create advertisements using the ELM method and determine the performance of these advertisements. Conclusion: SME owners can create advertisements using the ELM method during the training period, conduct independent evaluations of advertisements, the sales performance of these SMEs tends to increase compared to the previous by creating advertisements using the ELM method, practical modules are provided so that making advertisements using same method can be practiced for current and future needs.

\section{A B S T R A K}

Latar belakang: Seiring dengan berkembangnya alat media digital membuat arah pemasaran bergeser dari yang konvensional menjadi berorientasi media social. Namun hal ini tidak mudah dijamah oleh kalangan pebisnis UMKM. Banyak dari mereka tidak memiliki literasi yang tinggi, tidak memiliki coding skill IT. Selain itu, memodali sebuah website sekaligus maintenance merupakan biaya yang sangat besar bagi mereka. Kenyataan tersebut mendorong para UMKM untuk melirik kesempatan lain, yakni dengan menggunakan media sosial. Meskipun demikian, ternyata UMKM tersebut belum memanfaatkan penggunaan media sosial tersebut dengan iklan yang persuasif. Tujuan: Pengabdian masyarakat untuk pendampingan pembuatan iklan media sosial dengan kaidah persuasion concept-elaboration likelihood model (ELM) pada UKM di Surabaya ini, bertujuan untuk memecahkan masalahmasalah tersebut. Metode: Metode yang digunakan adalah (1) diskusi; (2) pelatihan dan pendampingan pembuatan iklan; (4) evaluasi/pemantauan. Hasil dari kegiatan pengabdian masyarakat ini UMKM mitra yang didampingi telah mampu membuat iklan media sosial yang persuasif dan dapat meningkatkan kinerja pemasaran mereka. Hasil: Para pemilik UMKM ini mampu membuat iklan dengan metode ELM dan mampu mengetahui kinerja iklan tersebut. Kesimpulan: Pemilik UMKM dapat membuat iklan dengan metode ELM pada masa pelatihan, dapat melakukan evaluasi mandiri terhadap iklan, kinerja penjualan dari UMKM tersebut cenderung meningkat dibandingkan sebelum pembuatan iklan dengan metode ELM, dibekali dengan modul praktis sehingga pembuatan iklan dengan metode yang sama nantinya dapat dipraktikkan sesuai kebutuhan saat ini dan masa depan.

\author{
ARTICLE INFO \\ Received 10 December 2020 \\ Revised 2 September 2021 \\ Accepted 23 October 2021 \\ Online 10 November 2021 \\ *Correspondence (Korespondensi): \\ Phima Ruthia Dwikesumasari \\ E-mail: \\ phima_ruthia@vokasi.unair.ac.id
}

Keywords:

Social media; Digital

marketing, Persuasive theory; Elaboration Likelihood Model; SMEs; Surabaya

Kata kunci:

Media sosial; Pemasaran digital; Teori persuasif; Elaboration Likelihood Model; UMKM; Surabaya 


\section{PENDAHULUAN}

Jawa Timur merupakan salah satu propinsi di Indonesia dengan pertumbuhan UMKM yang cukup pesat. Data hingga tahun 2016, Propinsi Jawa Timur telah mencatat sebanyak 6.825.931 UMKM dengan total tenaga kerja yang terserap oleh sektor UMKM ini sebanyak 11.117.439 tenaga kerja (Sensus Ekonomi, 2016; SUTAS, 2018). Surabaya sebagai ibukota propinsi Jawa Timur juga memiliki peran yang cukup baik dalam menopang sektor UMKM ini demikian juga dengan Madiun, yang memiliki industri UMKM yang cukup berkembang. Hingga Tahun 2018, berdasarkan Sensus Ekonomi 2016 dan SUTAS 2018 Surabaya telah mencatat sebanyak 260.762 UMKM dan Madiun sebanyak 168.393 UMKM. Meskipun demikian, ternyata UMKM tersebut belum memanfaatkan penggunaan media sosial tersebut dengan iklan yang persuasif.

Selama ini masih banyak UMKM khususnya di Surabaya dan Madiun ternyata belum memiliki komunikasi pemasaran dalam bentuk iklan digita di media sosialnya yang memberikan efek persuasif. Hal ini terjadi karena selama ini para pengusaha UMKM hanya secara otodidak dalam belajar. Hal ini sudah tentu secara psikologis tidak memberikan penekanan persuasi dan konsumen tidak melihatnya sebagai hal yang menarik perhatian sehingga imbasnya adalah calon pelanggan akan sambal lalu saja membaca iklannya, hanya sekedar tahu dan tidak ada dorongan untuk membeli.

Berdasarkan pengamatan kami, komunikasi iklan media sosial ini sering terjadi pada UMKM yang pemilik usahanya adalah generasi tua dan StartUp Milenial namun bukan dari kalangan yang terdidik (tidak mengenyam bangku perkuliahan), sehingga literasi mereka terhadap ilmu komunikasi pemasaran sangat minim. Untuk itu, sangat perlu dilakukan pendampingan kepada mereka untuk memperbaiki dan mengajarkan ilmu komunikasi periklanan yang persuasif dengan pendekatan Elaborate Likelihood Model (ELM) ini. Pendekatan ELM adalah suatu pendekatan peruasi yang berupaya untuk menjelaskan bagaimana pelanggan memproses rangsangan secara berbeda. Hasil dari ELM ini adalah perubahan sikap, dan perilaku. Pendekatan ELM ini berargumen bahwa fokus dari aktivitas stimuli yang digunakan akan membuat audiens (dalam hal ini adalah pelanggan) untuk memproses dan mengevaluasi pesan, mengingatnya, dan kemudian memtuskan untuk menerima atau menolaknya (Petty and Cacioppo, 1986).

DarI analisis situasi pelaku UMKM pada sub-bab sebelumnya, maka dapat diidentifikasi permasalahan yang dialami oleh pelaku UMKM adalah sebagai berikut: a. Pelaku usaha UMKM secara geografis berada pada wilayah dengan karakteristik kota metropolitan dengan populasi yang padat, dan daya beli yang relatif tinggi sehingga mereka dapat memilih berbagai alternatif produk dan memiliki akses media sosial. Implikasinya adalah pelaku UMKM akan memiliki peta persaingan yang sangat sengit untuk memperoleh pangsa pasar. b. Banyaknya para pesaing yang juga memanfaatkan kekuatan media sosial untuk komunikasi pemasarannya. c. Media online menjadi dibanjiri oleh iklan UMKM sehingga komunikasi iklan yang persuasif dan menarik perhatian merupakan kekuatan strategis yang harus dikuasai para pemilik usaha. Untuk meningkatkan penjualan mereka. d. Minimnya literasi mengenai komunikasi pemasaran pada para pemilik UMKM khususnya yang bergenerasi lama dan umkm baru namun dari kalangan yang kurang memiliki akses pendidikan tinggi.

Solusi dari permasaralan mitra adalah memberikan dan meningkatkan wawasan, literasi digital marketing serta keterampilan mitra mengenai pengetahuan membuat iklan digital yang memberikan efek persuasi kepada pelanggan dan calon pelanggan untuk terdorong melakukan pembelian. Para UMKM, melalui pengabdian masyarakat ini akan diberi wawasan dan pelatihan untuk mampu membuat iklan yang persuasif tersebut untuk meningkatkan kesadaran pelanggan, nilai merek dan penjualan produk usahanya.

Sasaran pengabdian masyarakat Prodi DIII Manajemen Pemasaran adalah pelaku UMKM di Surabaya. Pengabdian masyarakat tersebut dilakukan dengan adanya pertimbangan bahwa diharapkan masyarakat melalui peningkatan keterampilan ini dapat mampu menjaga keberlanjutan dan meningkatkan pertumbuhan usaha sehingga mereka memiliki kekuatan untuk menggerakkan perekonomian dirinya dan masyarakat sekitarnya. Luaran yang didapatkan adalah modul dan penerapan iptek di masyarakat.

\section{METODE}

Metode yang kami gunakan adalah dengan pendampingan dengan beberapa pemilik-pemilik UMKM yang akan dilakukan secara berkala dan bertahap dengan memanfaatkan teknologi sosial media. Hal ini dikarenakan Pengabdian masyarakat yang baik bukanlah hanya masalah pengumpulan massa dan seringkali hanya berformat ceramah dan presentasi yang belum tentu semua mitra merasakan manfaatnya, Untuk itu, terdapat alternatif metode pengabdian masyarakat dengan metode daring. Hal ini dilakukan untuk mendukung kebijakan Pemerintah dan membantu mengurangi 
dampak pandemi, tetapi tidak mengurangi esensi dari kegiatan pengabdian masyarakat itu sendiri.

Kegiatan pengabdian masyarakat secara daring ini diharapkan tetap mampu menjaga kesinambungan dengan melakukan pembinaan dan hingga mitra dapat mandiri yang lebih intens sehingga kualitas kemitraan menjad lebih baik. Harapan masa datangnya adalah UMKM yang berpartisipasi akan dapat menjadi Mitra strategis bagi kami Prodi DIII Manajemen Pemasaran, Fakultas Vokasi, Universitas Airlangga dalam mengembangkan mata kuliah dan penelitian khususnya bidang Komunikasi Pemasaran, e-bisnis untuk UMKM, bahkan mitra praktikum mahasiswa kami kedepan.

Pelaksanaan kegiatan pengabdian masyarakat ini terdiri dari beberapa tahapan dengan menggunakan beberapa metode yang berbeda. Survey pendahuluan ini adalah survey awal untuk menentukan topik pengabdian masyarakat yang dibutuhkan oleh masyarakat. Survey ini dilakukan dengan melakukan pengamatan pada fenomenafenomena terkini yang dihadapi oleh masyarakat baik yang berasal dari pengamatan langsung maupun berdasarkan literatur-literatur ilmiah. Survey ini juga bertujuan untuk menentukan objek pengabdian masyarakat sehingga lebih fokus dan meningkatkan keahlian agar implementasinya bisa berjalan berkesinambungan. Hasil dari survey ini adalah ditentukannya topik pendampingan iklan media sosial.

Tahap kedua adalah survey mitra. Setelah menentukan topik, maka tahapan selanjutnya adalah menentukan mitra UKM yang ingin mendapatkan manfaat dari pendampingan pembuatan iklan media sosial. Survey ini diilakukan dengan metode convenience dan snowball, dimana mitra dicari terlebih dahulu pada relasi dan rekan terdekat untuk kemudian diteruskan pada UKM yang berminat. Setelah itu dilakukan kunjungan awal untuk menanyakan kesediaan mitra tersebut.

Tahap ketiga adalah persetujuan mitra. Kunjungan awal yang dilakukan sebelumnya menghasilkan permasalahan spesifik mitra yang berhubungan dengan iklan media sosial. Metode yang digunakan adalah diskusi. Kemudian jika mitra merasa bahwa program ini memberikan kemanfaatkan pada mitra, maka mitra setuju untuk didampingi dalam hal pembuatan iklan media sosial tersebut.

Tahap selanjutnya adalah pemberian modul. Sebagai langkah awal proses pendampingan, terlebih dahulu mitra diberikan modul yang berisi tentang teknik-teknik pembuatan iklan media sosial. Modul ini bertujuan untuk memberikan pengetahuan pada mitra dan tahapan kerjanya sehingga Mitra mampu melakukan sendiri di ruang kerjanya.

Tahapkelimaadalah diskusidanpendampingan Pembuatan Iklan Media Sosial. Setelah pemberian modul, maka dilakukan pendampingan pembuatan iklan media sosial. Pendampingan ini menggunakan metode diskusi intens dan personal via daring agar mitra paham langkah kerja dan dapat melakukannya dengan baik. Hal ini dilakukan agar iklan yang dibuat nantinya sesuai dengan tujuan mitra, desain produk dan merek produk, dan memenuhi harapan mitra atas iklan tersebut.

Tahap keenam adalah implementasi iklan media sosial. Setelah berhasil membuat iklan sesuai dengan yang diinginkan dan diharapkan oleh mitra, maka mitra mengunggahnya di media sosial yang telah dimiliki mitra. Jika belum memiliki media sosial, mitra dapat mulai membuatnya dengan mengikuti langkah-langkah yang dijelaskan di dalam modul serta memperoleh pelatihan dan pendampingan pula dari tim pengabdian masyarakat

Tahap terakhir adalah evaluasi Iklan Media Sosial. Setelah berhasil mengimplementasikan penayangan iklan di media sosial mitra, maka mitra akan memperoleh respon pelanggan atas iklan tersebut. Untuk dapat memberikan impact pada mitra, maka keseluruhan elemen tersebut dievaluasi. Seluruh elemen itu diharapkan mampu meningkat seiring dengan pembuatan iklan yang lebih baik dengan penggunaan media elektronik yang sedang menjadi tren. Evaluasi respon pelanggan dilakukan dengan survey pada 100 responden, yaitu pelanggan masing-masing mitra yang melihat dan/atau membeli produk mitra setelah periode posting iklan media sosial.

\section{HASIL DAN PEMBAHASAN}

Sesuai dengan tahapan pelaksanaan program pengabdian masyarakat, maka keseluruhan tahapan mulai dari survey pendahuluan hingga evaluasi berhasil dilakukan dengan baik dan lancar via daring dan dengan tetap melaksanakan protokol kesehatan yang ketat. Mitra berhasil melakukan pembuatan iklan media sosial sesuai kaidah persuasion concept - elaboration likelihood model dengan membaca modul, memperhatikan penjelasan, dan aktif mengikuti pendampingan dan pelatihan melalui diskusi intens dan personal (Gambar 1).

IKlan-IKlan tersebut kemudian diposting di media sosial yang dimiliki oleh mitra dan dilakukan kampanye dengan iklan-iklan tersebut selama kurang lebih 9 minggu. Selama 9 minggu tersebut, mitra melakukan pengamatan tentang respon pelanggan mengenai iklan yang mereka tayangkan di akun media sosialnya. Setelah itu dilakukan 
evaluasi mengenai iklan tersebut pada pelanggan dengan menggunakan kuesioner pada pelanggan. Tahapan evaluasi pelanggan tersebut juga disertai dengan evaluasi bisnis, yaitu efektifitas iklan media sosial, dimana mitra diwawancarai oleh tim pengabdian masyarakat dan sebagai penutup dari rangkaian acara pengabdian masyarakat periode tahun 2020. Iklan yang dibuat oleh para peserta tampak pada Gambar 1 hingga Gambar 3 perikut ini.

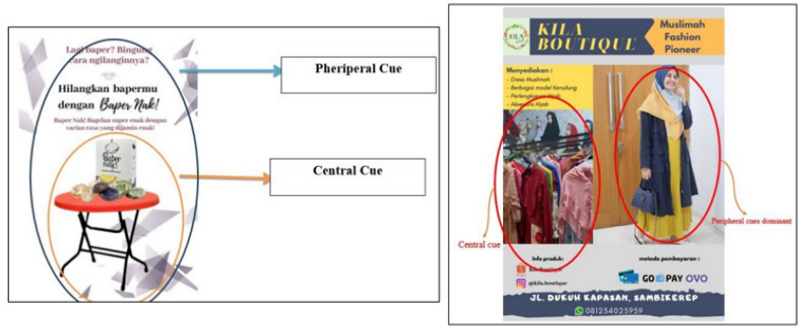

Gambar 1. Iklan Baper Nak dan Kila Boutique (2020)

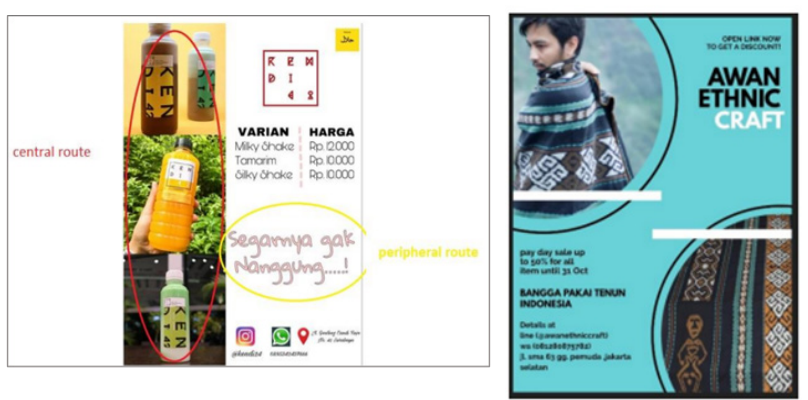

Gambar 2. Iklan Kendi42 dan Awan Ethnic (2020)

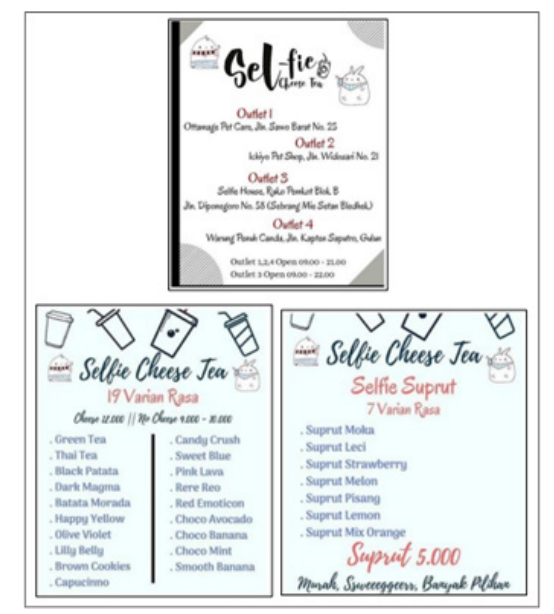

Gambar 3. Iklan Sel-fie Cheese Tea (2020)
Adapun hasil evaluasi konsumen tampak bahwa sebagian besar pelanggan relatif menyukai pesan iklan dan desain iklan yang dibuat oleh mitra (Tabel 1).Tetapi terdapat sebagian responden yang kurang menyukai warna iklan yang digunakan oleh mitra. Hal ini dikarenakan warna yang digunakan kurang cerah sehingga kurang menarik perhatian calon pelanggan. Hal ini menunjukkan bahwa meskipun telah dilakukan pendampingan dan pelatihan, kreativitas dari mitra sangat diperlukan untuk membuat suatu iklan menjadi menarik di mata pelanggan. Selain itu, tampak juga sebagian besar pelanggan berminat untuk mengunjungi akun media sosial mitra dan melakukan pembelian, namun hal ini masih belum optimal.

Tabel 1. Evaluasi Konsumen Terhadap Iklan

\begin{tabular}{|c|c|c|c|c|c|c|}
\hline Variabel & $\begin{array}{c}\text { Mitra } \\
1\end{array}$ & $\begin{array}{c}\text { Mitra } \\
2\end{array}$ & $\begin{array}{c}\text { Mitra } \\
3\end{array}$ & $\begin{array}{c}\text { Mitra } \\
4\end{array}$ & $\begin{array}{c}\text { Mitra } \\
5\end{array}$ & $\begin{array}{c}\text { Rata- } \\
\text { rata } \\
\text { Hasil }\end{array}$ \\
\hline Pesan iklan & 3,57 & 4,53 & 4,02 & 4,69 & 4,68 & 4,298 \\
\hline Warna iklan & 2,80 & 4,66 & 4,18 & 3,64 & 4,67 & 3,984 \\
\hline Desain iklan & 4,11 & 4,20 & 4,19 & 3,88 & 4,68 & 4,212 \\
\hline $\begin{array}{l}\text { Minat } \\
\text { berkunjung }\end{array}$ & 4,21 & 4,66 & 4,29 & 3,90 & 4,88 & 4,388 \\
\hline $\begin{array}{l}\text { Minat } \\
\text { pembelian }\end{array}$ & 4,23 & 4,66 & 4,26 & 3,90 & 4,88 & 4,386 \\
\hline
\end{tabular}

Keterangan :

Mitra 1 = Baper Nak; Mitra 2 = Kila Boutique; Mitra 3 = Kendi; Mitra 4 = Sel-Fie Cheese Tea; Mitra 5 = Awan Ethnic dari UMKM Putri Wilis

Berdasarkan hasil wawancara dengan mitra, diperoleh hasil kampanye iklan media sosial mengalami segi peningkatan dari jangkauan iklan dan nilai penjualan aktual setelah posting iklan tersebut di media sosial (Tabel 2). Hasil ini memberikan ide penelitian anjutan mengenai hubungan antar jangkauan iklan dengan penjualan produk untuk membuktikan adanya variabelvariabel lain yang memoderasi atau memediasi pengaruh kedua variabel tersebut.

Tabel 2. Efektivitas Iklan Media Sosial

\begin{tabular}{lcccccc}
\hline \multicolumn{1}{c}{ Variabel } & Mitra 1 & Mitra 2 & Mitra 3 & Mitra 4 & Mitra 5 & Kesimpulan \\
\hline Jangkauan Iklan & Meningkat & Meningkat & Meningkat & Meningkat & Meningkat & $\begin{array}{c}\text { Terjadi peningkatan } \\
\text { jangkauan iklan }\end{array}$ \\
Penjualan & Naik 10\% & Naik 30\% & Naik 14\% & Naik 10\% & Naik 20\% & $\begin{array}{c}\text { Terjadi kenaikan } \\
\text { penjualan }\end{array}$ \\
\hline
\end{tabular}

Keterangan :

Mitra 1 = Baper Nak; Mitra 2 = Kila Boutique; Mitra 3 = Kendi; Mitra 4 = Sel-Fie Cheese Tea;

Mitra 5 = Awan Ethnic dari UMKM Putri Wilis 


\section{KESIMPULAN DAN SARAN}

Kegiatan ini memberikan dampak positif bagi peserta pendampingan, diantaranya 1) Pemilik UMKM dapat membuat iklan dengan metode ELM pada masa pelatihan; 2) Pemilik UMKM dapat melakukan evaluasi mandiri terhadap iklan untuk mengevaluasi apakah iklan tersebut telah cukup menarik bagi pelanggan untuk mempersuasi mereka dalam melakukan keputusan pembelian; 3) Hasil pendampingan menunjukkan bahwa kinerja penjualan dari UMKM tersebut cenderung meningkat dibandingkan sebelum pembuatan iklan dengan metode ELM; dan 4) Pemilik UMKM dibekali dengan modul praktis sehingga pembuatan iklan dengan metode yang sama nantinya dapat dipraktikkan sesuai kebutuhan saat ini dan masa depan.

Dalam proses evaluasi program pengabdian masyarakat ini, terdapat beberapa hal yang menjadi simpulan program diantaranya selama proses kegiatan pengabdian masyarakat yang telah dilakukan, sebagian besar kegiatan berjalan lancar dan baik. Mitra mampu bekerja sama dengan baik dan puas akan pendampingan dan pelatihan yang diberikan oleh tim. Kemudian mitra dapat menindaklanjuti program dengan memberikan saran terkait topik-topik yang mungkin bisa dijadikan lanjutan program atau program baru pada kegiatan pengabdian masyarakat tahun depan. Mitra-mitra tersebut bahkan ingin dipanggil kembali jika ada program yang menarik lagi tahun depan. Materi yang disampaikan oleh tim pun juga mampu dipahami dengan baik oleh mitra, tercermin pada kemampuan mitra untuk membuat iklan sesuai dengan modul dan hasil diskusi oleh tim. Pengetahuan dan minat mitra akan pemasaran melalui media sosial dinilai mengalami peningkatan.

\section{UCAPAN TERIMA KASIH}

Terima kasih kami ucapkan kepada Fakultas Vokasi Universitas Airlangga atas dukungan yang diberikan sehingga pengabdian kepada masyarakat prodi DIII Manajemen Pemasaran tahun 2020 dapat berjalan dengan lancar. Penulis menyatakan tidak ada konflik kepentingan dengan pihak-pihak yang terkait dalam kegiatan pengabdian kepada masyarakat ini.

\section{DAFTAR PUSTAKA}

Petty, R.E., Cacioppo, J.T., 1986. The elaboration likelihood of persuasion. Adv. Exp. Soc. Psychol. Vol. 19, Pp. 123-205.

Sensus Ekonomi, 2016. Dinas Koperasi dan UKM Propinsi Jawa Timur [WWW Document]. URL http://diskopukm.jatimprov.go.id/info/dataukm (diakses 11.28.20).

SUTAS, 2018. Dinas Koperasi dan UKM Propinsi Jawa Timur [WWW Document]. URL http:// diskopukm.jatimprov.go.id/info/data-ukm (diakses 11.28.20). 